\title{
Continuidades y cambios de la Matriz Sociopolítica en Chile desde la reinauguración democrática*
}

\author{
Gloria de la Fuente**
}

\begin{abstract}
La distribución social y no el crecimiento es lo que dominará las políticas del nuevo milenio. Para detener la inminente crisis ecológica es imprescindible que el mercado no se ocupe de asignar los recursos o, al menos, que se limiten tajantemente las asignaciones del mercado. De una manera o de otra, el destino de la humanidad en el nuevo milenio dependerá de la restauración de las autoridades públicas.
\end{abstract}

(Eric Hobsbawm, Historia del Siglo XX)

\begin{abstract}
Resumen
Utilizando el enfoque que proporciona la Matriz Sociopolítica (MSP) para el análisis de las transformaciones sociales y considerando dos elementos centrales de la matriz, esto es, el régimen político y el modelo de desarrollo, se examinan las principales características de la MSP clásica o Estatal Nacional Popular (MENP) en Chile durante parte importante del siglo XX, para luego analizar el efecto que tiene el golpe de Estado de 1973 y la dictadura en Chile en estos componentes de la MSP. Con este análisis a la vista, el documento estudia sobre aquellos elementos de la MSP que presentan patrones de continuidad, cambio y tendencias emergentes en Chile desde la recuperación de la democracia en 1990.
\end{abstract}

Palabras clave: Régimen político - modelo de desarrollo - matriz sociopolítica.

\begin{abstract}
The document reviews the main characteristics of the classical Sociopolitical Matrix (MSP) or State National Popular (MENP) in Chile for a large period of the twentieth century, using the approach provided by the MSP for the analysis of social transformations. It considers two central elements of the matrix, the political regime and the model of development. Later, the effect of the 1973 coup and the following dictatorship in Chile in these components of the MSP is analyzed. With this analysis in view, the author explores the patterns of continuity, change and emerging trends in Chile in those two elements, since the return of the democracy in 1990.
\end{abstract}

Keywords: Political regime - model of development - sociopolitical matrix.

* Esta ponencia es una versión parcial de un trabajo realizado el año 2004 por María Elena Acuña y Gloria de la Fuente titulado: "Nuevos desafíos, viejas tensiones. La articulación de la Matriz Sociopolítica en Chile 1925-2004", en el marco de un proyecto sobre la matriz sociopolítica en cinco países de la región, bajo la coordinación de Manuel Antonio Garretón, Marcelo Cavarozzi, Peter Cleaves y Jonathan Hartlyn. Dicho proyecto fue también presentado en el XXI Congreso Mundial de Ciencia Política, realizado en Santiago el año 2009. Sus trabajos serán publicados íntegramente en un libro de próxima aparición.

** Cientista Política y egresada del magíster en la disciplina en la Pontificia Universidad Católica de Chile, mención Instituciones y Procesos Políticos. Ha sido profesora en las universidades ARCIS, Academia de Humanismo Cristiano y del Diplomado de Negociación y Análisis Político del INAP, Universidad de Chile. Actualmente se desempeña como analista de la División de Estudios del Ministerio Secretaría General de la Presidencia. Hasta el 2008 fue Consejera de la Asociación Chilena de Ciencia Política y en la actualidad es miembro del Consejo Académico del Instituto Igualdad. 


\section{INTRODUCCIÓN}

El análisis desarrollado a partir del enfoque proporcionado por la Matriz Sociopolítica (MSP) -también Ilamado megaenfoque- intenta explicar las transformaciones sociales a partir de la interrelación de múltiples variables que dan lugar a procesos que ocurren de manera simultánea y que inciden en la configuración de las sociedades, su cultura, su economía y su sistema político. En otras palabras, proporciona una perspectiva holística a procesos políticos que no pueden ser explicados por teorías unicausales (Garretón et al., 2003).

Chile, al igual que muchos países de la región latinoamericana asiste, a principios del siglo XX, a la configuración de una MSP Ilamada "Estado-céntrica" o "Estatal-nacionalpopular". En el ámbito institucional, esta MSP se caracterizaba por un Estado que desempeñaba un papel central como símbolo de unidad, asignador de recursos, referente de la acción colectiva y articulador de la política social. La acción social durante el desarrollo de esta matriz estaba subordinada a la política y, en este cuadro, los partidos políticos tuvieron enorme importancia en la intermediación entre la sociedad civil y el Estado. El modelo de desarrollo durante gran parte del desarrollo de esta matriz se basó en la sustitución de importaciones, adquiriendo la industria nacional un papel fundamental.

En el caso chileno, el quiebre institucional producido por el golpe militar de 1973 inicia un proceso de descomposición de la MSP. No sólo se reprimió toda actividad social derivada de la acción política, sino que también propició la destrucción del modelo de Estado. Asimismo, se introdujo una visión distinta respecto al modelo de desarrollo del país, que liberalizaba la economía y privatizaba el sector público. En este escenario, el aparato estatal, el gran proveedor de certezas sociales, se repliega cediendo terreno al mercado y asumiendo un nuevo rol subsidiario, enfatizando su ámbito en la regulación.

En este cuadro, la recuperación de la democracia en Chile en 1990 y todo el proceso derivado de la transición, enfrenta a los sucesivos gobiernos al desafío de la construcción de un nuevo paradigma orientado, por una parte, a la recuperación y consolidación de la democracia y, por otro, a la configuración de una nueva forma de concebir el modelo de desarrollo basado en las profundas transformaciones sociales ocurridas con el quiebre de la matriz Estado-céntrica. Ello da lugar al surgimiento de una nueva MSP. El presente artículo abordará las continuidades, cambios y tendencias emergentes de la MSP en Chile, a partir de la recuperación de la democracia en 1990 y abordando dos de sus aspectos principales: el régimen político y el modelo de desarrollo.

\section{PRINCIPALES CARACTERÍSTICAS DE LA MATRIZ SOCIOPOLÍTICA ESTATAL NACIONAL POPULAR (MENP) EN CHILE (1925-1973)}

\subsection{Régimen político}

Las constituciones se erigen como momentos fundacionales relevantes en un país, particularmente en aquellos con una tradición legalista importante como sucede con la 
mayoría de los países latinoamericanos. La Constitución de 1925 es, en este sentido, un momento trascendental para la MSP por cuanto fija elementos importantes de ésta: el carácter presidencial del régimen político y el fortalecimiento del Ejecutivo, la separación de la Iglesia Católica y el Estado y la exclusión del campo político deliberante de las Fuerzas Armadas ${ }^{1}$. No obstante, el modelo de relaciones que daba, por una parte, gran poder a la figura del Presidente, generaba altos grados de conflictividad institucional producto de las tensiones entre el Ejecutivo y Legislativo.

El esquema político de derecha, centro e izquierda (tres tercios) producía un empate técnico en términos de representación popular y tenía un efecto importante en el control de los actores políticos en un marco global altamente ideologizado producto de las tensiones propias del periodo de Guerra Fría.

Las Fuerzas Armadas, excluidas del campo político deliberante, fueron erigidas sin embargo como garantes, siendo convocadas a la acción política tal como sucedería en 1973. Durante el siglo XX son reiteradas las muestras de politización al interior de las Fuerzas Armadas ("Grupo de Oficiales Seleccionados", "PUMAS" y "Tacnazo", asesinato del General Schneider e incorporación de militares al gobierno del Presidente Allende) (Prats, 1985)².

Los partidos políticos constituyen en el periodo las organizaciones sociales de mayor importancia en el país. Sus redes geográficas, así como sus influencias políticas y culturales se extienden por todo el territorio nacional. La red que constituían los partidos políticos dotó al sistema de representación popular de una diversidad de actores, e intereses puestos en diálogo y tensión en el marco de las definiciones primordiales de la estrategia de desarrollo que permitía que las demandas políticas y sociales fueran acogidas en el sistema político, en los programas de gobierno y en las políticas públicas.

La ampliación de la ciudadanía, lograda a través de la extensión y garantías para el ejercicio del derecho a voto, fue importante para el funcionamiento del sistema político. En este marco son importantes dos momentos. Primero, al finalizar la década del 40, se

1 La Constitución Política del año 1925 zanjó la disputa sobre las ventajas y desventajas del sistema presidencialista versus el parlamentarista, ocasionadas a partir de la Revolución de 1891, año en el que se produjo una guerra civil en el país que terminó con el gobierno del Presidente José Manuel Balmaceda.

2 En 1924, la precaria situación económica en que se encontraban los militares chilenos provoca el conocido episodio del "ruido de sables" en el Congreso Nacional. Posteriormente, tras un golpe de Estado en 1925, es la Junta Militar la que provoca el retorno temporal de Alessandri a la presidencia para promulgar la Constitución de 1925. El Coronel Ibáñez, líder indiscutido del movimiento de las Fuerzas Armadas, fue miembro del gabinete presidencial y llega al poder en su condición de militar en 1927, y cuando lo hace en 1952, ya se ha convertido en un líder populista pero ha abandonado su condición de militar. Así también, al interior del Ejército se crean grupos secretos como los GOS ("Grupo de Oficiales Seleccionados") o PUMAS ("Por un Mañana Auspicioso"), que tienen claramente una visión específica sobre la situación política nacional y, particularmente, del Ejército. Se produce también el "Tacnazo" durante el gobierno de Frei Montalva, como respuesta del sentir mayoritario de la oficialidad respecto de la indiferencia del gobierno para solucionar los problemas que aquejaban al Ejército, episodio cuya fatal consecuencia es el quiebre de la verticalidad del mando. El asesinato del General Schneider en 1970 a manos de un grupo ultraderechista, también golpea fuertemente al Ejército y polariza aún más las posiciones en su interior. 
otorga el derecho a voto pleno a las mujeres después de casi 80 años de demandas. El segundo de ellos se produce a fines de la década del 60 cuando los sectores campesinos fueron incorporados como un actor social y político dándoles un rol en el proyecto político provocado por la creciente modernización de la economía.

Esta lógica inclusiva y de agregación de demandas de la sociedad fue un elemento central en la MSP Estado-céntrica. En este cuadro, se producen dos hitos relevantes: la Reforma Agraria y la Ley de Juntas de Vecinos y Organizaciones Populares, de 1968, ambos elementos centrales en la ampliación de la ciudadanía.

Los partidos políticos y los movimientos sociales jugaron a partir de su capacidad de generar un imaginario de integración, pertenencia y acción colectiva. Su origen está, por tanto, vinculado a "lugares culturales" de articulación social, siendo el pluripartidismo no sólo una característica del sistema político hasta la década del 70, sino que fue también una expresión de la amplitud del sistema de representación política, desde el punto de vista ideológico.

\subsection{Modelo de desarrollo}

La estrategia de desarrollo, hasta la década del 70, se articuló en función del Modelo de Sustitución de Importaciones con su correlato en la industrialización y en la urbanización. El Estado por su parte se orientó a conjugar sus roles en la producción, el empleo y la educación como supervisor e interventor.

El Modelo de Sustitución de Importaciones se implementó como una estrategia para superar la crisis de los erarios fiscales provocada por la caída de las exportaciones del salitre en la década del 30, que durante varias décadas había sido un símbolo del progreso de la República.

El carácter industrializador de la estrategia de desarrollo incidió en el fortalecimiento de los roles del Estado como productor y empleador a través de la creación de numerosas agencias, como, por ejemplo, la Corporación de Fomento de la Producción (CORFO), en 1939, destinada a centralizar la estrategia estatal de desarrollo productivo industrial, y fomentando al mismo tiempo las actividades, asesorías y proyectos en manos del sector privado; la Empresa Nacional de Electricidad (ENDESA), en 1943; la Empresa Nacional de Petróleo (ENAP), en 1945, y la Compañía de Aceros del Pacífico (CAP), en 1946.

Esta estrategia permitió la industrialización y urbanización de algunos polos regionales de desarrollo, disminuyó considerablemente el desempleo originado por la crisis del modelo anterior e impulsó la organización institucional y tecnológica. Asimismo, hizo surgir a un fuerte sector obrero que se organizó en sindicatos y, a través de éstos, se constituyó en un actor político.

En un país que a mediados del siglo XX cifraba sus esperanzas en un modelo de desarrollo con industrialización, los trabajadores eran tanto fuerza de trabajo como símbolos del progreso y de la continuidad de las raíces profundas de los modos de ser chilenos. 
Sin perjuicio de ello, la estrategia de desarrollo recalcó el aspecto capitalista de la economía con intervención de capitales extranjeros y dependencia de la economía internacional (Ffrench Davis, 1988).

La administración del modelo obligó a los sucesivos gobernantes ${ }^{3}$ a tomar medidas de carácter correctivo que no siempre fueron aceptadas por la población o los empresarios, y muchas veces el rechazo a alguna de ellas se transformó en una herramienta política significativa. De hecho, hacia la década del 50 se observa cierta decadencia del modelo, producto de algunas deficiencias del proceso de industrialización, el estancamiento de la agricultura y las presiones inflacionarias (Ffrench Davis, 1999). El gobierno del Presidente Allende profundiza una serie de medidas económicas reformistas que venían desde el período de Frei Montalva, pero esta vez ligadas principalmente a la estructura de propiedad industrial ${ }^{4}$. La oposición a estas medidas por parte de algunos sectores sociales contribuyó a la agudización del sentimiento de crisis política e institucional en el país, alterando la dinámica de interrelación de los actores políticos.

\section{GOLPE DE ESTADO DE 1973, ¿QUIEBRE O DESESTRUCTURACIÓN DE LA MSP?}

El golpe de Estado que se esgrime en un primer momento como un mecanismo de recomposición del sistema, sería a la postre el inicio de un proceso de ruptura de la MSP Estado-céntrica.

A partir del año 1973, el Poder Ejecutivo quedó a cargo del presidente de la Junta de Gobierno Militar y no de las Fuerzas Armadas, lo que evitó la rotación del cargo y personalizó el régimen en la figura de Pinochet (Moulián, 1997). De esta manera, desde 1973, la Junta Militar gobernó haciendo uso de los estados de excepción de la Constitución de 1925.

No obstante, bajo esas condiciones, el régimen no podría legitimarse totalmente, razón por la cual desde muy temprano comenzó a funcionar la llamada "Comisión Ortúzar", cuyo mandato principal fue proponer a la Junta de Gobierno una nueva Constitución Política, finalmente modificada por la propia Junta y sometida a plebiscito en 1980. Con este hito los militares logran crear su proyecto sociopolítico, provocando un quiebre significativo con la MSP Estatal, Nacional y Popular.

Uno de los elementos más relevantes de esta Constitución Política es que estableció la manera en la cual se produciría la transición hacia la democracia, con un plebiscito en el año 1988, donde se sometió a escrutinio la continuidad del sistema político tutelado por los militares versus la posibilidad de una transición a un sistema democrático (Garretón, 1988, 1995). La opción vinculada a la prolongación de la tutela militar resultó derrotada por un estrecho margen, y se da comienzo a un proceso que desembocará en la democratización (incompleta) del país (Garretón, 2009).

\footnotetext{
Ibáñez (1952-1958), Alessandri (1958-1964), Frei (1964-1970) y Allende (1970-1973).

La nacionalización del cobre constituye uno de los ejemplos más significativos de progreso y desarrollo.
} 
El régimen militar generó un proceso de modernización excluyente y autoritario (Castells, 2006) en reemplazo de la democracia integradora que existía anteriormente y que propendía a la solidaridad y la confianza como formas básicas para la generación de las identidades sociales y culturales.

Respecto al modelo de desarrollo, se observa también un intento por relevar la impronta fundacional del régimen. Los militares tenían claridad respecto a la necesidad de iniciar reformas, aunque no tenían certeza respecto a cuál debía ser el camino a seguir. Una primera señal importante en este sentido fue la incorporación al gobierno de un grupo de economistas formados en la Universidad Católica que habían profundizado sus estudios en la Universidad de Chicago -principal escuela del laissez faire-. Este grupo de profesionales, a los que se les Ilamó "Chicago Boys", se instaló en la Oficina de Planificación Nacional (ODEPLAN) y logró en poco tiempo sentar las bases de un nuevo modelo de desarrollo económico para Chile. La fórmula económica neoliberal se planteó entonces como una superación radical de las fórmulas precedentes (Collier y Sater, 1998).

Esta nueva estrategia produjo no sólo una reordenación económica, sino también cambios en los roles del Estado, terminando paulatinamente con sus funciones sociales: la salud y la previsión social fueron entregadas al sector privado a través del sistema de Instituciones de Salud Previsional (ISAPRE) y Administradoras de Fondos de Pensiones (AFP). Otro tanto sucede con el sistema educativo, donde el Estado se desprende del rol docente que había asumido desde la década de 1930. Esto sucede a través de una reforma propiciada a partir de la Constitución de 1980 y que termina en la promulgación de una Ley Orgánica Constitucional que permitió, sin mayor restricción, la incorporación de capitales privados en el sistema educativo. Este proceso coincide con la aplicación de las políticas de ajuste estructural indicadas por el Banco Mundial y el FMI para superar la crisis económica de los 80, que fueron aplicadas de manera ortodoxa y que implicaron, por un lado, la reducción del gasto del Estado precisamente en las áreas sociales y, por el otro, la privatización de empresas en áreas claves, incluso en sectores considerados estratégicos como el transporte, la energía y las telecomunicaciones, las que fueron traspasadas al sector privado en condiciones poco claras (Monckeberg, 2001). En el nuevo paradigma de desarrollo, al Estado le competía un rol regulador en la economía. Sin embargo, éste sólo fue alcanzado de manera parcial recién a mediados de la década del 90.

En suma, el régimen militar significó en términos de la MSP:

- Un quiebre del régimen político democrático y el intento de refundación y legitimación mediante una nueva Constitución Política.

- Deteriorar la articulación política al punto de suprimir toda expresión de participación y conculcar las libertades públicas.

- Un quiebre en la relación Estado-ciudadanos-partidos.

- Impulsar una serie de reformas estructurales (Ilamadas de primera generación) orientadas a abordar el déficit estructural de la economía, disminuyendo el gasto público, privatizando 
las empresas estatales y, en general, disminuyendo la intervención del Estado en la economía, instalando un modelo autoritario liberal excluyente (Castells, 2006).

- Provocar altos grados de exclusión para la población, privilegiando políticas orientadas al mercado. Durante las dos crisis que sufrió la economía en el periodo (1974-1976 y 1982-1984), el PIB cayó un 13 y un 16\%, respectivamente. Las tasas de desempleo bordearon el 30\% y se generó una creciente situación de pobreza, que hacia 1990 alcanzaba el $40 \%$.

- Deteriorar la legislación para proteger a los trabajadores y una baja sustantiva en las remuneraciones, pensiones e ingreso mínimo respecto a 1970. Desmantelamiento y reducción del tamaño y rol del Estado. Con ello, se reduce a una expresión mínima el componente "estatal" y "popular" de la MSP predominante del siglo XX.

\section{REARTICULACIÓN DE LA MSP: TENDENCIAS EMERGENTES A PARTIR DE LA RECUPERACIÓN DEMOCRÁTICA EN 1990}

La reinauguración democrática ocurrida en 1990 constituye un hito para la configuración de la MSP actual. No es posible comprender la forma en que se articula el Estado, la estructura político-partidaria y la sociedad civil o base social (Garretón, 1993), sin entender la importancia que tuvo la transición hacia el régimen democrático en Chile después de 17 años de autoritarismo ${ }^{5}$. Como se ha señalado anteriormente, la Constitución de 1980 contenía definiciones sobre la continuidad del régimen político diseñado en el gobierno militar, el cual consideraba la realización de un plebiscito en 1988 para someter a la decisión popular la disyuntiva entre la opción Sí (a la continuidad representada en la figura misma de Augusto Pinochet) y el No (representada por todos los grupos políticos opositores al régimen militar), que a la postre resultaría ganadora en dicho evento.

La oposición al régimen militar enfrentó dividida este evento. Por un lado, se encontraba una coalición política Ilamada Concertación de Partidos por el No (que agrupaba a la Democracia Cristiana, así como a partidos políticos escindidos de ella durante los 60 y 70, a diversidad de sectores socialistas agrupados tanto en el propio Partido Socialista como en un nuevo referente Ilamado Partido por la Democracia, al Partido Humanista y al Partido Radical); por el otro, se encontraban el Partido Comunista que, aunque hizo un llamado a votar por el No, fue excluido de la Concertación.

Al triunfar el No en el plebiscito celebrado el 5 de octubre de 1988, se fijaron elecciones presidenciales y parlamentarias para diciembre de 1989. La Concertación -que para ese entonces pasó a llamarse Concertación de Partidos por la Democracia- presentó un candidato

5 En este sentido, se adscribe a la tesis que afirma que la transición a la democracia termina en el momento en que Aylwin asume la presidencia en 1990. No se comparte la visión de aquellos que sostienen que la transición continúa una vez instalada la democracia, dada la existencia de temas pendientes con el pasado producto de la herencia autoritaria. Estos Ilamados "enclaves autoritarios", si bien están presentes, escapan a la naturaleza propia de la transición y son más bien el reflejo de una democracia incompleta. 
de consenso antipinochetista que se enfrentó a un candidato de continuidad del gobierno militar, continuidad sobre todo en lo económico ${ }^{6}$.

En la oposición al régimen de Pinochet, si bien se logró un consenso respecto del candidato presidencial no sucedió lo mismo en lo relativo a las elecciones parlamentarias, por lo cual el Partido Comunista no formó parte de las listas parlamentarias de la Concertación. Este hecho ha venido a configurar un elemento central de una nueva MSP, la arquitectura institucional heredada que establece marcos sobre los cuales funciona la democracia. En efecto, producto del sistema electoral binominal (propiciado a través de la Constitución de 1980) se incentiva la política de coalición, excluyendo a los partidos pequeños que prefieren no entrar en esta dinámica, perdiendo la amplitud ideológica del sistema político observada con anterioridad al régimen militar, pero también amenazando la desaparición de estas entidades partidarias ${ }^{7}$.

Ello sin duda influye en la percepción de la calidad de la política y hace muy difícil el tratamiento de temas que atañen a las minorías ya sean éstas de género, étnicas, sexuales o políticas -como los movimientos antineoliberalismo- que son importantes en el contexto cultural de la globalización. En este cuadro, parte importante de la dinámica política que produce la movilización social se aleja de la actividad política tradicional dada por los partidos.

El temor de una regresión autoritaria fue parte del discurso y la práctica política durante el gobierno de Patricio Aylwin (1900-1994), debido a que fue central en este gobierno la administración del conflicto con los militares ${ }^{8}$. Durante el Gobierno de Eduardo Frei, en tanto, si bien esta amenaza tiende a disiparse (particularmente con la salida de Augusto Pinochet de la Comandancia en Jefe del Ejército en 1998), los hechos terminan demostrando cuán presente estaba la herencia dictatorial en Chile con la detención de Pinochet en Londres, pese a que se habían producido al menos dos elecciones parlamentarias legítimas (1989 y 1993) y se había celebrado una ceremonia de traspaso de mando presidencial entre civiles, producto de un proceso eleccionario competitivo y abierto.

En la nueva MSP se hacen visibles nuevos temas y nuevas demandas insatisfechas por la democracia actual. Es así como el ejercicio de los derechos ciudadanos -más allá del sufragio-, los derechos sexuales y reproductivos, la construcción de un multiculturalismo que permita enfrentar de una manera menos polarizada la situación de los pueblos originarios,

\footnotetext{
Estos fueron Patricio Aylwin y Hernán Büchi, además del conservador Francisco Javier Errázuriz.

7 Pese a que el PC consigue tres escaños parlamentarios, desaparece en la elección de 2009, dado que no consigue el umbral mínimo de votos para legitimar su vigencia.

8 En general, el gobierno de Patricio Aylwin debió concentrar parte importante de sus esfuerzos en mantener dentro de límites tolerables la amenaza de la regresión autoritaria y sostener el modelo de "democracia de los acuerdos" que había ayudado a contener el conflicto social y a alcanzar la victoria para la Concertación de Partidos por la Democracia (coalición que agrupa a partidos de centro y centro-izquierda en Chile: Democracia Cristiana, Partido por la Democracia, Partido Radical Social Demócrata y Partido Socialista) en las elecciones presidenciales de 1989. Aunque la amenaza no desaparece totalmente en el gobierno de Frei -Pinochet continúa al frente de las Fuerzas Armadas hasta 1998-, sí se observa que ésta se hace cada vez menor.
} 
son cuestiones que no han logrado ser recogidas con suficiente fuerza en el discurso público de los distintos actores y, si lo han hecho, han sido más desde una lógica de política pública que desde un reconocimiento abierto de derechos.

Otro aspecto pendiente dice relación con la exclusión generada por el modelo de desarrollo instalado durante la dictadura y mantenido en democracia. De esta forma, el tema de la equidad y la distribución de la riqueza en el país sigue siendo un asunto gravitante en la realidad social y política, transformándose en un elemento conflictivo no sólo en las definiciones ideológicas sobre la redistribución, sino que también en las distintas alternativas de políticas públicas que estas visiones ofrecen ${ }^{9}$.

Por su parte, el relativo avance en el tema de las violaciones a los derechos humanos durante la dictadura se convierte en un elemento constitutivo de la nueva matriz que irrumpe en la memoria colectiva con la aparición de ciertos hitos como: la detención de Pinochet en Londres (1998-2000), los procesos judiciales y las condenas que siguen algunos militares en retiro y los anuncios del Ejecutivo de buscar nuevas formas de reparación para las víctimas y sus familiares, o los avances de las investigaciones sobre el magnicidio del Presidente Frei Montalva en la década de los 80. En este sentido, es importante considerar que durante muchos años, tanto las Fuerzas Armadas como los partidos de derecha que apoyaron el régimen militar, negaron sistemáticamente la existencia de violaciones a los derechos humanos durante este período. Con posterioridad se reconoce la verdad de los hechos, aunque aún no haya gestos de responsabilidad personal frente a ellos.

De esta manera, el conflicto parece ya no focalizarse sólo en la demanda de verdad-sobre la cual el avance es bastante indiscutible- como sí en cambio en la demanda de justicia y reparación, aún insatisfecha. La sociedad chilena ha vivido en una permanente lucha por la imposición de significados sobre el "pasado", razón por la cual, si bien ha prevalecido una narrativa sobre la memoria, fundamentalmente propiciada por los gobiernos de la Concertación, ésta no ha logrado ser hegemónica (Huneeus, 2000b; Lechner y Güell, 1999) ${ }^{10}$.

9 Un debate permanentemente presente ha sido la posibilidad de generar políticas redistributivas a través de alzas de impuestos o tributos, iniciativa resistida principal, aunque no únicamente, por sectores empresariales y de derecha. El argumento utilizado generalmente tiene que ver con el desincentivo que esta alternativa podría provocar en la producción y el funcionamiento del mercado. Sin duda este es uno de los aspectos relevantes del asentamiento del modelo económico neoliberal instalado en dictadura.

10 Tres hitos se observan en este ámbito. En primer lugar, el informe emanado de la Mesa de Diálogo, creada durante el gobierno de Eduardo Frei Ruiz-Tagle, que reunió a diversos actores sociales -excepto, paradójicamente, a la Agrupación de Familiares de Detenidos Desaparecidos- involucrados en los hechos que llevaron al quiebre institucional de 1973 y que dio cuenta de las sistemáticas violaciones a los derechos humanos. En segundo lugar, el Informe sobre Prisión Política y Tortura de la llamada Comisión Valech, que entrega al Presidente de la República en el 2004 un abordaje a la situación de los derechos humanos ya no desde los detenidos desaparecidos, como había sido hasta ahora, sino que también desde aquellos que sufrieron las consecuencias del régimen y que están aún vivos. En dicho documento están contenidas las declaraciones de 35.000 personas sometidas a apremios ilegítimos y torturas durante el gobierno de Pinochet. Este documento y el Ilamado "Informe Rettig" -elaborado en el gobierno de Patricio Aylwin-constituyen los más grandes esfuerzos de los gobiernos postautoritarios por generar documentos que den cuenta de las sistemáticas violaciones a los derechos humanos cometidas por el régimen de Pinochet. Por último, la creación del Museo de la Memoria en 
La nueva MSP se caracteriza así por las consecuencias de estos quiebres que a su vez se interrelacionan con algunos elementos de continuidad observados en el desarrollo de la MENP y su descomposición. En este sentido, el presidencialismo (instalado definitivamente a partir de la Constitución de 1925 y reafirmado en la de 1980) y la búsqueda por la legitimidad dada por las Cartas Fundamentales, sigue siendo un elemento central, valorado como un símbolo de legitimación por parte de la dictadura, que traspasa la ruptura de la matriz anterior y que encuentra expresión en la configuración actual ${ }^{11}$.

En este cuadro, las rupturas más significativas se encuentran en lo que respecta al rol del Estado, ya que su carácter de guía de los procesos económicos, sociales y políticos se ve progresiva, aunque no completamente, disminuido. De esta manera, uno de los elementos que de forma más marcada se hereda del proceso de descomposición de la MENP es el nuevo rol que asume el Estado y que evidencia el giro de un Estado Empresario -dueño de empresas públicas y proveedor de la mayor parte de bienes y servicios- a un Estado Regulador (Rehren, 2000; Rivera, 2003). Este nuevo Estado Regulador se caracteriza por fijar el marco normativo en el cual se desarrollan las actividades de mercado, amparando su función en la idea de la existencia de fallas de mercado que obligan al Estado a normar y fiscalizar, pero no a intervenir en la provisión misma de estos servicios (Stiglitz, 1995) ${ }^{12}$. La nueva institucionalidad del Estado, entonces, ya no estará centrada en la manutención de empresas públicas, sino que en la generación de una nueva institucionalidad que norme y fiscalice la provisión de estos servicios ${ }^{13}$.

Por otra parte, los partidos políticos que en la MENP aglutinaban intereses de distintos grupos sociales en un escenario de gran diversidad ideológica, se ven enfrentados a una creciente apatía por la participación política formal y a una creciente dificultad para capturar fidelidad partidaria en los procesos eleccionarios. Al mismo tiempo, los partidos son testigos de la penetración de lógicas de mercado en la competencia por el voto, donde el candidato, visto como un producto de las encuestas y el marketing, reemplaza muchas veces la encarnación de la ideología. A lo anterior se une el creciente desinterés de la ciudadanía por la actividad pública y la mayor valoración que ha cobrado la vida privada y las nuevas formas de consumo.

el gobierno de la Presidenta Michelle Bachelet, constituye un espacio cuyo propósito es reconstruir la memoria histórica de los hechos ocurridos en Chile entre 1973 y 1990.

11 A este respecto, parece interesante constatar que durante la campaña presidencial del año 2009 el tema de una nueva Constitución para a ser una de las propuestas más relevantes de la candidatura de la Concertación, planteando también la necesidad de reformar el hiperpresidencialismo que caracteriza al régimen político en Chile. Todo ello en respuesta a la necesidad de, después de 20 años de gobiernos democráticos, asumir una nueva agenda más ligada a temas de futuro y menos a la herencia autoritaria que vio nacer y dio identidad a esta coalición política.

12 Las fallas de mercado a las que se alude son: fallas de la competencia, como pueden ser los monopolios naturales -muy comunes en los servicios básicos como gas natural, electricidad o agua potable- y otras externalidades negativas de la producción de bienes y servicios.

13 Las superintendencias son ejemplos de ello. 
En relación con lo anterior, en la nueva MSP se asiste a una baja evaluación ciudadana de la actividad política, los políticos y sus instituciones. A este respecto, la respuesta de la clase política ha sido generar algunas estrategias de adhesión tales como la "política denuncia", por un lado, y "la farandulización de la política", por el otro ${ }^{14}$. Probablemente estas formas de neopopulismo constituyen una manera de sustituir la falta de distinción ideológica entre los distintos bloques políticos.

Por otra parte, el modelo de desarrollo neoliberal impulsado por el gobierno militar no encontró férreas resistencias luego de reinstalada la democracia en Chile ${ }^{15}$. Esto se explica en un primer momento por la necesidad de contener el conflicto y por el temor de la élite política a la posibilidad de una regresión autoritaria. No obstante, se observa paulatinamente una marcada orientación a introducir algunas correcciones al modelo de desarrollo que sin embargo no implican una crítica profunda. De este modo, el desafío de la equidad y la igualdad se hacen parte del discurso político habitual y, en esa medida, el gasto público orientado a políticas sociales tiende a crecer.

En la nueva matriz no se trata sólo de administrar el modelo de desarrollo basado en las leyes del mercado, sino que también de hacer que éste se comporte de manera tal que sus ventajas alcancen para todos, cuestión fundamental en el cuadro de una democracia que quiere contar con altos grados de legitimidad por parte de sus ciudadanos. En este sentido, aunque en ningún caso logran resolver el gran problema de exclusión social suscitado por el actual modelo de desarrollo, cobran importancia medidas redistributivas tales como la reforma educacional y los programas impulsados durante el gobierno de Eduardo Frei; la reforma al sistema de salud y el Programa Chile Solidario, diseñados y ejecutados por la administración de Ricardo Lagos, que han pretendido responder a la necesidad de mejorar las condiciones de acceso a servicios sociales y la calidad de vida de los sectores más desposeídos del país, y la creación de una "Red de Protección Social" en la administración de la Presidenta Michelle Bachelet, cuyo principal componente es la generación de un sistema de prestaciones del Estado que se haga cargo de la infancia a la vejez, siendo sus principales componentes el Sistema de Atención a la Primera Infancia y la Reforma Previsional.

Estas políticas implementadas por los gobiernos democráticos son de gran importancia, porque si bien no corrigen lo sustantivo del modelo, tienden al menos a palear los índices

14 Algunos parlamentarios, abusando de su condición de fiscalizadores de la acción del Ejecutivo, han apostado por realizar graves denuncias ante los medios de comunicación, sin que necesariamente tengan suficientes antecedentes para efectuarlas. Por su parte, y como hemos insistido, muchos alcaldes, parlamentarios e incluso personeros de gobierno han centrado esfuerzos en crear estrategias comunicacionales que les permitan estar de manera constante en los medios, sin que necesariamente esta presencia signifique aportar nuevos contenidos.

15 El modelo de desarrollo instalado en Chile al que hemos llamado "neoliberal" se caracteriza por un amplio papel asignado al mercado, por la privatización de los medios de producción y, en consecuencia, un cambio sobre la organización social del país. Las principales transformaciones económicas del modelo se focalizaron en los campos fiscal, financiero, laboral, relaciones económicas con el exterior y propiedad pública de los medios de producción. Más adelante se introdujeron también cambios importantes al sistema de previsión (Ffrench-Davis, 1999). 
de un notable deterioro de la distribución del ingreso en Chile y una excesiva concentración de la riqueza heredada del régimen militar. De la misma manera, el gobierno autoritario dejó en su partida una baja tasa de inversión bruta por trabajador y leyes laborales sesgadas contra éstos. Así también, el deterioro alcanza una baja en las remuneraciones, pensiones e ingreso mínimo respecto a 1970. Por último, el gasto público en salud, educación, previsión social y vivienda había decaído en un $22 \%$ promedio. La realidad descrita era incompatible con la existencia de un régimen democrático con grados aceptables de conflicto social y gobernabilidad. De esta manera, la preocupación por los temas de equidad y pobreza pasó a ocupar el mismo nivel que aquellos ligados a los equilibrios macroeconómicos, por cuanto se entendía que sólo ambos podrían alcanzar los equilibrios macrosociales deseados ${ }^{16}$.

De esta manera, la década del 90 destaca por la adopción de algunas iniciativas relevantes en materia económica (Ffrench-Davis, 1999). Las principales fueron:

- La Reforma Tributaria de 1990, que permitió aumentar el gasto social de manera significativa, permitiendo iniciar un proceso de mejora a la salud y la educación.

- La Reforma Laboral, que permitió el fortalecimiento de las organizaciones sindicales y la autodefensa de los trabajadores. Aunque ésta no ha llegado en ningún caso a los niveles observados en la MENP.

- Las mejoras al salario mínimo y de las asignaciones familiares, que han beneficiado a los chilenos del quintil más pobre. El porcentaje de la población considerada pobre pasó de $38,6 \%$ en 1990 a $20,6 \%$ en el 2000 .

- La producción de bienes y servicios es cerca de un 90\% más alta que a fines de la década anterior.

- El crecimiento promedio anual de la economía llegó a un 6,5\%, a pesar de la severa contracción experimentada en 1999 por efecto de la crisis asiática y el ajuste interno a sus consecuencias. Se debe tomar en cuenta que el promedio de crecimiento de la década anterior fue de 3,5\%.

- En diez años el país duplicó el orden de magnitud de sus exportaciones, pasando de US\$ 8.000 millones a fines de los 80, a US\$ 16.000 millones a fines de los 90 . Además, las exportaciones industriales se han incrementado de manera muy importante.

- La deuda externa del país (expresada como porcentaje del PIB) disminuyó de un 58\% en 1990 , a un $52 \%$ en 1999. Además, la deuda pública representaba en 1989 un $75 \%$ de la deuda total. En 1999 esta cifra se redujo al 17\%, correspondiendo el resto del endeudamiento al sector privado.

16 Huneeus (2000a) señala que durante los primeros seis años de gobiernos de la Concertación (1990-1996) se dictó un total de 492 leyes relativas a regulación, distribución o cuestiones particulares relacionadas con asuntos de diversa índole. 
- Respecto a la inflación, que en 1990 crecía a un ritmo de 27,3\%, en 1999 los precios crecieron sólo un 2,3\%.

- De la misma forma, la adopción de estrategias macroeconómicas más eficientes, que tendieron a mejorar la regulación del Estado frente a flujos de capital, permitió sortear con mayor éxito las crisis económicas externas como las de Argentina y México en 1995.

Junto a las reformas al modelo neoliberal, a la nueva MSP se le incorpora otro elemento fundamental al modelo de desarrollo: la apertura al comercio internacional. Chile adoptó un modelo de apertura económica que implicó la adopción de una economía de mercado y la supresión de todas las barreras impuestas durante la MENP al comercio internacional, no obstante, esta política unilateral carecía de un marco contractual que permitiese mejorar las condiciones de Chile para competir en el comercio internacional.

En este sentido, los gobiernos democráticos han generado estrategias que se orientan tanto a fortalecer los vínculos comerciales como los diplomáticos. Ello, ayudado por el fenómeno de la globalización tanto de mercados como de información, ha contribuido a que Chile haya firmado (o esté en proceso de hacerlo) una serie de Tratados de Libre Comercio (TLC) con diversos países en América, Asia y Europa.

Asimismo, el país ha orientado su política exterior a posicionar la imagen de Chile en el mundo, de manera tal de mejorar los niveles de confianza internacional. De esta forma, a partir de la administración de Ricardo Lagos, se propició una serie de medidas que se tradujeron en que Chile formara parte del Consejo de Seguridad de la Organización de Naciones Unidas (ONU), el envío de misiones de paz a Haití, el nombramiento de un chileno como el embajador de la ONU en Haití para superar la crisis humanitaria existente en ese país, la realización de la cumbre de APEC en Chile durante el 2004 y la elección de Insulza como secretario general de la OEA en el 2005. Todos estos constituyen hitos que apuntan en la dirección de mejorar los vínculos diplomáticos y/o comerciales.

Los gobiernos democráticos de los 90 optan por una estrategia comercial de regionalismo abierto, cuyos componentes son fundamentalmente:

- Estrategia unilateral, que implica la adopción de políticas de aranceles bajos y parejos, cuestión que, como se señaló, se venía desarrollando desde el gobierno autoritario.

- Estrategia multilateral, a través de foros u órganos comerciales como son la APEC, la OMC o ALCA, respaldada a partir de los 90 por la legitimidad del régimen político democrático.

- Estrategia bi o plurilateral, que implica Acuerdos de Complementación Económica (ACE) y Tratados de Libre Comercio (TLC) entre uno o varios países. Estrategia adoptada por los gobiernos chilenos a partir de 1993, con el primer Acuerdo de Complementación Económica firmado con Bolivia. 
Chile ha trabajado en las tres direcciones, combinando además los esfuerzos en materia comercial y diplomática. Para los gobiernos de la Concertación, los logros más importantes son los derivados de los TLC con Canadá, México, Centroamérica, Estados Unidos, la Unión Europea, Corea del Sur y China. Esta estrategia se ha visto favorecida por las condiciones que presenta la globalización a través del flujo de información existente y las facilidades para el transporte de mercancías y personas de un lado a otro. Asimismo, Chile ha sido aceptado en la OCDE, organismo internacional que agrupa a las naciones más desarrolladas y avanzadas del planeta, siendo el primer país de Sudamérica en ingresar a dicho organismo.

En los últimos años, el gobierno ha puesto un especial énfasis en las consecuencias positivas de los TLC en tanto catalizadores de cambios culturales y legales, como por ejemplo la generación de compatibilidades en las legislaciones laborales para adecuarlas al derecho internacional, las medioambientales o las de derechos de propiedad.

Tal como se señalaba con anterioridad, uno de los componentes que se presenta como importante en la MSP actual y que resiste el proceso de descomposición, es el carácter presidencialista y constitucionalista del régimen político chileno. El peso del Poder Ejecutivo es indiscutible en términos políticos y simbólicos. La personalización del régimen en la figura del Presidente de la República parece ser una característica que por períodos se exacerba, configurándose incluso como un hiperpresidencialismo ${ }^{17}$. De la misma forma, la vocación constitucionalista del régimen político chileno implica que cualquier cambio de este componente en la matriz actual tendrá que pasar necesariamente por un mecanismo de legitimidad legal ${ }^{18}$.

Por otra parte, y tal como se señaló con anterioridad, el modelo de desarrollo instalado y la consecuente disminución del Estado y cambio de roles del mismo, no sólo han tenido repercusiones en el plano económico, sino que también en el político, traduciéndose en un notable aumento del mercado como mecanismo de asignación de recursos (Rehren, 2000; Rivera, 2003). La relación entre política y mercado se acrecienta (Silva, 2002) y los gobiernos deben generar estrategias de estabilidad y crecimiento macroeconómico que a su vez les permitan atraer inversión y generar mayores recursos para la inversión en políticas públicas que, en última instancia, sirvan para generar mejores condiciones para proyectarse políticamente en el futuro.

A partir de este nuevo escenario de irrupción del mercado y achicamiento del Estado es que se ha discutido el tema de la Reforma del Estado como una tarea pendiente de los últimos tres gobiernos de la Concertación de Partidos por la Democracia (Rivera, 2003). En la configuración actual de la matriz, esta reforma ha sido entendida básicamente como

17 Por ejemplo, los estilos de liderazgo de la figura del Presidente dicen mucho de la estructura de conformación de equipos y de la forma en que se realiza la toma de decisiones. Esto da cuenta de si estos equipos son meramente informadores de su gestión o consultivos en relación a las decisiones del Primer Mandatario.

18 Se entiende que el mecanismo de legitimidad legal, a diferencia de uno basado en la tradición o en procesos de transformación liderados por un líder carismático, tienen un fuerte componente de apego a las leyes y normas vigentes. 
la transformación del aparato administrativo del Estado en respuesta a la nueva realidad impuesta desde el modelo de desarrollo. En este sentido, se observa la adopción de una serie de políticas que apuntan en esta dirección y a la creación de comités o agencias desde el Ejecutivo encargadas de encabezar este proceso transformador ${ }^{19}$. Cuando se habla de reforma o modernización del Estado, de lo que se trata en realidad es de dar cuenta de un cambio en la gestión del aparato administrativo, pero que evidencia las nuevas tensiones en la articulación de la matriz que no han sido suficientemente consideradas en el diseño de políticas con esta orientación.

Por otra parte, resultan importantes las dinámicas que configuran la participación política actual. Mientras que en la MENP la centralidad de la acción política y la emergencia de nuevos grupos sociales fue clave, por cuanto aseguró la amplitud ideológica del sistema de representación e implicó la fortaleza de la institucionalidad partidaria, en la MSP actual la intermediación del mercado juega un rol central en la participación política. En palabras de Moulián (1997):

“En el Chile actual donde la economía genera formas postizas y simuladas de proteger al individuo de la inequidad distributiva, dotándolo del crédito que proporciona una esperanza concreta, factible, que no pueden entregar las grandes narraciones etéreas, es fácil caer en la tentación de una vida que transcurre entre el agobio del trabajo y el descanso del mall o la televisión. En ese marco ¿para qué podría servir la política, la participación, la actividad pública?" (Moulián, 1997: 108).

En la pregunta por el cambio de sentido y configuración de la participación política es necesario considerar: la influencia de un diseño político-institucional que ha favorecido la mantención de las mayorías políticas y la sobrerrepresentación de la segunda fuerza política en desmedro de las minorías (sistema binominal), la pérdida del contenido ideológico de los partidos producto del quiebre de la lógica Este-Oeste ${ }^{20}$, la decadencia de la imagen de lo público y la desvaloración del rol que han cumplido instituciones como las ONGs. De hecho, vale la pena considerar que la idea misma de ideología o politización de lo político y lo social es presentada como problema para el consenso, el normal funcionamiento o para la estabilidad de la idea país. Casi de manera constante se escuchan Ilamados a no politizar la economía, la pobreza, la justicia, los derechos humanos, etc. Este discurso incluso ha logrado penetrar a los partidos políticos de todos los sectores. Entonces, en la misma medida en que se insiste en la falta de participación política, se articula un discurso público que muestra lo político como una cualidad negativa de la vida social. En este sentido, a nivel

19 Durante el gobierno de Eduardo Frei se creó el Comité Interministerial de Modernización de la Gestión Pública que, como su nombre lo dice, estaba compuesto por los principales ministros de Estado. En el gobierno de Ricardo Lagos, en tanto, se crea el Proyecto de Reforma y Modernización del Estado, dependiente del Ministerio Secretaría General de la Presidencia. En el gobierno de Michelle Bachelet, por su parte, se enfatiza el impulso de una agenda de Reforma del Estado, liderada por el Ministro del Interior.

20 Lógica internacional fundamental en tanto generó las directrices para los partidos de izquierda durante la matriz Estado-céntrica, y que se rompe con el fin de la Guerra Fría y la caída de la Unión Soviética. 
ideológico se introduce un elemento de tensión en la articulación de la matriz, donde el sentir ciudadano y el discurso público oficial se distancian enormemente.

La diferenciación ideológica en el país ha ocasionado que se mantenga una distinción importante entre el pasado -ideologizado- y el futuro -no ideologizado-. En este plano Chile parece estar dividido (Huneeus, 2000b) y se instala entonces el consenso como un valor social altamente apreciado pero que no constituye una propuesta para compartir el futuro sino un miedo compartido a revivir los conflictos del pasado (Lechner y Güell, 1999). El "imaginario colectivo" de lo chileno parece así diluirse (PNUD, 2002).

La decadencia de la imagen de lo público y especialmente del mundo político es una característica relevante de la nueva matriz y un elemento diferenciador respecto a su configuración anterior. Los partidos pierden relevancia y el sistema electoral binominal vigente no permite la creación de nuevos movimientos sociales con capacidad de articularse en un partido con probabilidad de éxito, ya que el sistema electoral -uno de los mencionados enclaves autoritarios- tiende a fomentar la existencia de pactos, dejando fuera a aquellos partidos que privilegien la competencia individual o de minorías, tal como antes se señaló.

A lo anterior, se suma el decaimiento que han sufrido muchas ONGs en el transcurso de la estabilización del régimen democrático, lo que se debe básicamente a la disminución de los recursos internacionales que se explicaban por la necesidad de generar actores políticos capaces de recuperar la democracia. Esto ha implicado necesariamente la desaparición de muchos de estos organismos o la disminución o invisibilización de su contribución en la generación de un tejido social políticamente activo.

La nueva MSP se caracteriza por contar con partidos políticos con un discurso que no apela a lo ideológico y donde las diferencias operan en el campo del modelo de desarrollo (plenamente aceptado por todo el espectro de partidos con representación parlamentaria) o en las interpretaciones sobre el pasado reciente, aunque este último factor tiende a perder la fuerza que tuvo en el discurso público partidista de principio de los 90. La aparición de nuevos temas en la agenda pública (bioética, medio ambiente, equidad de género, globalización e identidades) que los partidos no son siempre capaces de recoger, genera enormes dificultades para que éstos puedan expresar e interpretar a los nuevos actores y movimientos sociales que emergen en la actualidad (Garretón, 2000).

\section{v. CONCLUSIÓN}

Si bien la transición de una nueva MSP es mucho más amplia que el movimiento de un régimen político a otro (transición), lo cierto es que pasadas dos décadas desde la recuperación de la democracia en Chile es posible observar la emergencia de algunos elementos que marcan una cierta tendencia para una nueva MSP.

Respecto al régimen político la democracia se ha legitimado y ha logrado consolidarse, propiciando una serie de transformaciones que han contribuido a superar, aunque no del todo, el marco institucional heredado de la dictadura. En la actualidad, la discusión se centra en 
la "calidad" de la democracia. Sin perjuicio de esto, esta arquitectura institucional heredada provoca en aquellos temas considerados relevantes para la profundización democrática, como el cambio al sistema electoral o la reforma constitucional, una real posibilidad de cambio.

Por su parte, si bien el modelo de desarrollo neoliberal ha sido reformado de manera paulatina a través de políticas públicas orientadas a mejorar particularmente la desigualdad -tema persistente en el discurso de la clase política-, no se ha logrado aún modificar de forma sustantiva su influencia. Ello es singularmente difícil en un sistema que propicia el "empate político" para los acuerdos, en particular legislativos, y que por ende impide transformaciones sustantivas.

En suma y siguiendo a Lechner (1999), se producen tres paradojas en la configuración de una nueva MSP, cuya emergencia, a dos décadas de recuperada la democracia en Chile, se hacen evidentes:

- Modernización y malestar social difuso (atomizado). Los enormes avances en desarrollo humano (PNUD, 2009) no necesariamente se traducen en sensación de bienestar para la población y requieren, por tanto, un tratamiento menos convencional desde las políticas públicas y más desde la recuperación del sentido de lo público y la política misma.

- Administración de un régimen político cuya arquitectura institucional fue elaborada en dictadura. Esta configuración no sólo ha acompañado su desarrollo, sino que también ha puesto límites a su transformación, provocándose, a la larga, un pie forzado que puede tener consecuencias complejas para la democracia.

- Modelo de desarrollo con reformas, más incluyente, que mejora el nivel de vida de la población, pero que administra parte importante del modelo heredado en dictadura (ISAPREs, AFPs y Educación).

\section{BIBLIOGRAFÍA}

Castells, Manuel (2006): Globalización, desarrollo y democracia: Chile en el contexto mundial, Fondo de Cultura Económica, Santiago.

Cavarozzi, Marcelo (1996): El Capitalismo Político Tardío y su Crisis en América Latina, Serie Estudios Sociales, Ediciones Homo Sapiens, Santiago.

Collier, Simon y William Sater (1998): Historia de Chile 1808-1994, Cambridge University Press, Cambridge.

Ffrench-Davis, Ricardo y Óscar Muñoz (1988): Crecimiento, industrialización y políticas comerciales en América Latina: 1950-86, CIEPLAN, Santiago.

Ffrench Davis, Ricardo (1999): Entre el Neoliberalismo y el Crecimiento con Equidad: tres décadas de política económica en Chile, Dolmen, Santiago.

Ffrench-Davis, Ricardo y Óscar Muñoz Gomá (2003): "Las políticas económicas y sus efectos", en Óscar Muñoz y Carolina Stefoni (coords.): El período del Presidente Frei Ruiz-Tagle, Editorial Universitaria, Santiago. 
Fuentes, Claudio (1996): El discurso militar en la transición chilena, FLACSO-Chile, Santiago.

Garretón, Manuel Antonio (1993): La crisis de la democracia, el golpe militar y el proyecto contrarrevolucionario, FLACSO-Chile, Santiago.

(1993): La faz sumergida del Iceberg, Ediciones CESOC-LOM, Santiago.

(2000): La Sociedad en que Viviremos, Colección Escafandra, LOM Ediciones, Santiago.

(2009): "Problemas Heredados y nuevos problemas en la democracia chilena: ¿hacia un nuevo ciclo?", en Gloria de la Fuente, Sergio Contreras, Paulo Hidalgo y Julio Sau (eds.): Economía, Instituciones y Política en Chile, Serie Estudios, Vol. IV, División de Estudios Ministerio Secretaría General de la Presidencia, LOM Ediciones, Santiago.

Garretón, Manuel Antonio y Malva Espinoza (1992): ¿Reforma del Estado o Cambio en la Matriz Sociopolítica, Serie Estudios Sociales Facultad Latinoamericana de Ciencias Sociales, FLACSOChile, Santiago.

(1995): Tendencias de Cambio en la Matriz Sociopolítica Chilena. Una aproximación empírica, Informe Final Proyecto Fondecyt 1930-282, m/s.

Garretón, Manuel Antonio, Marcelo Cavarozzi, Peter Cleaves, Gary Gereffi y Jonathan Hartlyn (2003): Latin America in the 21th Century: Toward a new Sociopolitical Matrix, North-South Center Press, University of Miami.

Huneeus, Carlos (2000a): "Los Cambios Institucionales al Sistema Económico durante la Transición a la Democracia en Chile. Del Neoliberalismo a la Economía Social de Mercado", Revista de Ciencia Política, I Vol. XX, № 2.

(2000b): Chile un país dividido. La actualidad del pasado, Catalonia, Santiago.

Lechner, Norbert y Pedro Güell (1999): "Construcción social de las memorias en la transición chilena", en Amparo Menéndez-Carrión y Alfredo Joignant (eds.): La Caja de Pandora. El retorno de la transición Chilena, Planeta/Ariel, Santiago.

Micco, Sergio y Eduardo Saffirio (2000): ¿Abandonar el Presidencialismo?: presidencia, quiebre y redemocratización en Chile, Centro de Estudios para el Desarrollo, Santiago.

Monckeberg, María Olivia (2001): El Saqueo de los Grupos Económicos al Estado Chileno, Ediciones B Chile S.A., Santiago.

Moulián, Tomás (1997): Chile Actual: Anatomía de un Mito, LOM-ARCIS, Santiago.

Muñoz, Óscar (1986): Chile y su industrialización: pasado, crisis y opciones, CIEPLAN, Santiago.

Nef, Jorge (1999): "Contradicciones en el "Modelo Chileno", en Amparo Menéndez-Carrión y Alfredo Joignant (eds.): La Caja de Pandora. El retorno de la transición Chilena, Planeta/Ariel, Santiago.

Prats, Carlos (1985): Memorias. Testimonio de un Soldado, Pehuén, Santiago.

Programa de Naciones Unidas para el Desarrollo (2002): Informe de Desarrollo Humano 2002: Nosotros los chilenos un desafío cultural, PNUD, Santiago.

(2009): Informe de Desarrollo Humano 2009: La manera de hacer las cosas, PNUD, Santiago.

Rehren, Alfredo (2000): “La Redemocratización de la Política Chilena: ¿Hacia una Democracia Capitalista?", Revista de Ciencia Política, Vol. XX, № 2, Santiago. 
Rivera, Eugenio (2003): Nueva, economía, gobierno electrónico y reforma del Estado, Editorial Universitaria, Santiago.

Siavelis, Peter (2000): "Continuidad y Cambio en el Sistema Partidista Chileno. Sobre los efectos de transformación de una Reforma Electoral", Revista de Ciencia Política, Vol. XX, № 2, Santiago.

Silva, Eduardo (2002): "Capital and the Lagos Presidency: Business as Usual?, Bulletin of Latin American Research, Vol. 21, № 3, julio.

Stiglitz, Joseph (1995): La Economía del Sector Público, Antoni Bosch editor S.A., Barcelona.

Vergara, Pilar (1985): Auge y caída del Neoliberalismo en Chile, FLACSO-Chile, Santiago.

Weyland, Kurt (1999): “La política económica en la nueva democracia chilena", en Paul Drake y Juan Jaksic (comps.): El Modelo Chileno: Democracia y desarrollo en los 90's, LOM, Santiago. 
